\title{
E-learning as a Toll for Higher Instruction: A Study into The Impacts of E-learning in Education
}

\author{
Shanavas Moosafintavida
}

Azteca University, Mexico, North America

Corresponding author: shanavas.musafi@gmail.com

Received: $22-09-2020$

Revised: $10-11-2020$

Accepted: 04-12-2020

\begin{abstract}
The recent advancements in info and Communication Technology (ICT) offer higher IT solutions to real-world issues. The education field has no exception, rising IT technologies and platforms are used often-times by the individuals in learning processes. Approach of learning and education ever-changing with the newest advancements in info and Communication Technology. The newest computing paradigm, that's cloud computing is often one among the simplest ways that of computing technology in instruction and e-learning. During this paper describes my planned design model of educational cloud and offers the thought of e-learning as a service. This describes however the cloud computing are often used effectively in e-learning method and sharing of resources of the educational institutes and providing the shut overlook on the protection of open access networks in higher educational establishments and the vision of technology for education. The objective of this analysis is to explore the scope for e-learning in instruction situation and to look at the e-learning content preparation and presentation tools. Therefore, it conjointly examines the appliance of e-learning in numerous sorts of methodologies employed in the planet to check the advantages of e-learning. It conjointly explores the challenges that may be moon-faced by e-learning within the world in order that it will study the long run of e-learning and to look at the attainable ways of latest introductions so as to grasp the meant /actual contribution of the paper like diffuse info relating to numerous e-learning tools and innovative ways of applications those are followed within the world, to assist the remainder of the participants learn the varied ways of e-learning, to impose the importance of e-learning for higher studies, to form the academicians understand the importance of e-learning in order that they are going to begin learning to push the e-learning method.
\end{abstract}

Keywords: e-learning, ICT (Info and Communication Technology)

How to cite this article: Moosafintavida, S. (2020). E-learning as a Toll for Higher Instruction: A Study into The Impacts of e-learning in Education. IJISC., 7(02): 85-95. 
There has been appreciable discussion a few comprehensive definitions of e-learning within which existing definitions cared-for mirror the researcher's specializations and their interests. For instance, historical influences meant that e-learning may well be seen by educators as Associate in Nursing ex gratia presentation of ancient delivery while specialists within the technical aspects of hardware and package differed by prioritizing ICT s effects on academic and education relationships [1]. Within the meanwhile, the impact of technology on education and on education ways brought a distinct focus to the talk. There is also as several definitions of e-learning as there are educational papers on the topic. It is clear from the on top of that another strand to the argument would be a science perspective that queries the impact of ICT on learners, learning teams and academic establishments. Withal, obtainable definitions of e-learning were not selected with full agreement amongst researchers, every of whom checked out the sector from a distinct angle. Considerably, as Associate in Nursing example of the means studies trusted the character of interest and specialization of the researchers, funding bodies, producers and programmers created evaluations of their business returns. The subsequent sections discuss those definitions of e-learning that evolved from distance learning, technology, and pedagogy [2].

\section{E-learning Tactics and Focus in Distance Learning}

One perspective in shaping e-learning springs from distance learning. Since e-learning evolved as a kind of distance learning, a study by correspondence, the which means of the term modified once ICT emerged. One among the foremost renowned definitions of distance learning involved an academic method within which a big proportion of the teaching was conducted by somebody remote from the learner [3]. This author additionally explained it as public education, typified by self-learning that was versatile and did not need the learner to attend a standard institution or be subject to constant oversight by lecturers. Visible of technological progress, distance learning enclosed the oversight of instructional establishments, wherever multimedia system provided mutual interactive communication between the parties of the tutorial method and support for autonomous learning, at synchronous or asynchronous times and in various places.

Therefore, it became a middle means or a compromise between ancient teacher-centered learning and student-centered learning. The link between distance learning and technology lingered in such the simplest way that the 2 ideas square measure conflated in some definitions. Associate degree example of this that is getting ready to the elaboration of the definition utilized in this study [4]. e-learning was the simplest way to deliver instructional content with its explanations and exercises and interaction, followed-up part or comprehensively in lecture rooms or remotely by advanced programs hold on computers or through networks. Similarly, characterised e-learning as learning systems to produce learning or coaching programs for learners and trainees at any time and in anyplace victimization ICT interactively like the web and computer network and conference, to produce associate degree interactive learning surroundings with multiple sources synchronous and asynchronous [5]. Indeed, the implications of effective use of technology to deliver learning were noted as economical in terms of your time and energy and were, therefore, a helpful substitute for ancient pedagogy [6].

Autonomous learning was currently related to ICTrelevance on-line access to learning resources, anyplace and anytime. Delivering learning content via electronic multimedia system and laptop networks to relinquish the learner the chance of dealing actively with the content and with the teacher and with peers, whether synchronous and asynchronous, further because the risk of the completion of the content within 
the time, place and pace that suits his circumstances and capabilities [7]. Therefore, starting as another that created education deliverable on the far side institutional boundaries, e-learning was later perceived as shaping the various sort of pedagogy.

\section{The Scientific Style of E-learning}

Researchers United Nations agency was intently centred on technological potentialities enclosed the widest variety of applications in their definitions of e-learning, supporting the inclusion of the acquisition and use of data distributed and expedited primarily by electronic means that with suggestions that this way of learning presently depends on networks and computers, however, can possibly evolve into systems consisting of a spread of channels (e.g. wireless, satellites, and technologies cellular phones, iPads) as they're developed and tailored [8]. The use of assorted technological tools for E-learning that square measure web-based, web-distributed, or web-capable for the needs of education [9]. Despite the argument that the effectiveness of e-learning cannot be equated with the multiplicity of technological applications used for its delivery, the statement confirmed that, if somebody is learning during an approach that uses data and communications technologies (ICT), they are victimisation e-learning [10]. E-learning is also defined as [11]: "a term covering a good set of applications and processes, like web-based learning, computer-based learning, virtual lecture rooms, and digital collaboration. It includes the delivery of content via web, intranet/extranet (LAN/WAN), audio and video, satellite broadcast, interactive TV, CD-ROM, and more." Additional list to incorporate TV, transportable, webcam, email, DVD/CD, website, telephone, audio-conferencing, audio graphics, videoconferencing as technological means that of delivering e-learning [12]. For e-learning, then, a good set of applications and processes were enclosed that were each net and computer-based, providing virtual lecture rooms, and digital collaboration. Its content may well be delivered by modes as numerous as web, intranet, audio and video, CD-ROM, satellite, product interactive TV and more.

\section{The Role of E-Learning in Education and Training}

These all-inclusive definitions comprised a range of hardware and software system, accustomed deliver e-learning, and therefore the systems necessary for economical and value effective education. As a departure from e-learning s identification with technology, the innovation as an: "approach for delivering electronically mediate, well-designed, learner-centered, and interactive learning environments to anyone, anyplace, anytime by utilizing the net and digital technologies as one with educational style principles [13]. Thus, the definition introduced the notion that technology ought to serve the needs of ancient pedagogy. The most accustomed gift the broader domain of development analysis activities on the applying of technologies to education. Nonetheless, it had been then established that technology should be controlled by pedagogues before it may besuggesting that of academic delivery [14]. Whilst flexibility offers a response to totally different approaches to learning and time and place constraints, e-learning created these priorities viable in order that learners might keep anyplace and study, however a good system capable of enabling the learners to speak with others and facilitate them to be told and grow completely was needed [15]. The E-learning Action arrange stressed the utilization of recent transmission technologies and therefore the net to enhance the standard of learning by facilitating access to resources and services still as remote exchanges and collaborations. E-learning was firmly cited among an academic 
community despite learners' selections of their own house and classified it as a sort of learning that relies on the utilization of electronic media for communication between lecturers and learners and therefore the institution [16]. The triangular relationships between pedagogy, technology and academic administration were a part of e-learning as a broad combination of processes, content and infrastructure victimization computers and networks to scale and/or improve one or a lot of vital components of a learning price chain, as well as management and delivery [17]. Despite the fascination with instrumentality, as shown higher than, e-learning cannot come about unless there is an easy explanation for combining the weather of technology, pedagogy, and administration. seeable of that the science specialise in the training surroundings and its positive and negative impacts on the development and composition of the college community and therefore the perceptions of learners should essentially be enclosed in studies of e-learning. The question remains whether the business sector's specialise in the expected returns is entirely pertinent to the present argument concerning e-learning's effectiveness however all previous definitions of e-learning have omitted it, while alternative characteristics are found throughout the examples offered higher than. These characteristics are sorted as follows:

* E-learning depends on the combined use of ICT and united or split networks, through interactive electronic devices, to deliver academic materials and messages between participants within the learning and teaching method [18],

* E-learning will not solely deliver content, however it includes all aspects of academic administration and coming up with from setting goals to assessment and analysis,

E-learning could complement room learning or be a substitute for it,

* E-learning is conducted below some style of supervising,

E-learning does not electronically duplicate the delivery of formal education however offers various approaches to teaching and learning and is consistently designed to supply inputs, processes, outputs, and feedback.

* Participants could interact in e-learning synchronously or asynchronously [19],

E-learning refers to the entire management of learning as within the terms Learning Management System (LMS) and Learning Content Management System (LCMS),

* E-learning facilitates self-learning, long learning, and personalization,

* E-learning is applicable to each academic and coaching functions whether among or outside establishments or in-service settings [20].

\section{The Elements of E-learning}

Reflection on vital factors for the institution of effective environments for e-learning enabled to develop a basic framework for e-learning or web-based learning. When it questioned what would be needed to supply widespread, versatile, and effective learning environments for all the learners despite their culture or circumstances. The answer projected with eight dimensions: education, technological, interface, evaluation, management, resources support, ethical, and institutional. Every dimension had sub-dimensions covering specific aspects of the e-learning atmosphere [21]. 


\section{The Technological Elements}

* The technological dimension observed problems regarding the infrastructure of e-learning environments. It enclosed the design of infrastructure and hardware and code.

* The interface style was the looks of the e-learning programs. This enclosed the look of the location, the pages and content, navigation, and usefulness tests [22].

* The resource support comprised on-line support and message, like technical support and skilled steerage. Khan showed that resources were needed to reinforce the active and interactive significance of the training atmosphere [23].

\section{The Administration elements}

* The management observed the upkeep of the training atmosphere and the distribution of knowledge relevant to its use.

* The institutional dimension enclosed body problems like rules and certification, budget and investment returns, data technology services, instructional development and promoting services. On one hand this dimension encompassed educational affairs, like supporting the teaching workers, instructional affairs, and the pressure of labor, the dimensions of categories, salaries, and material possession rights. On the opposite hand, it additionally provided for college students services like pre-school services and data on attending and programs, steerage and help in money matters concerning registration and the payment of premiums and enclosed supporting libraries and such different facilities as social support networks [24].

\section{The educational and moral elements}

* Pedagogical dimension observed teaching and learning. It comprised the goals and objectives, content analysis and educational style, apply strategies and techniques of its programs These embody simulation, training, non-public lessons, games and narrative stories and role-playing games, discussion, and interaction, modelling and cooperation and different such activities [25].

* The moral dimension observed social and cultural diversity, prejudice, and geographical diversity and the diversity of lecturers and acting systems together with legal problems like structure policy, and copyrights. Thus, the analysis enclosed associate assessment of learners and instruction and of the training atmosphere [26].

The eight dimensions by accentuation that each e-learning project was distinctive so, formulating queries specific to the issues associated with each project was essential. A technique to target the required issues was to grasp each dimension from the client's perspective whether neutral, learner, teacher, or worker. The exploration of each dimension would then highlight issues two-faced by each neutral. Throughout this way, the analysis might raise necessary issues and answer queries that may assist among the fashion of a useful atmosphere for e-learning. Thus, analysis studies would generate a comprehensive list of e-learning comes requirements. The history of e-learning clarifies and marking especially important changes to decide by universities, ministries, and governments, which may embody the social implications of e-learning tons of and tons of as technology can increase interactivity. Thus, another sketch of e-learning's development is appropriate here. Succeeding section considers the interactive developments among the sectors. 


\section{The Types of E-learning}

E-Learning allows the learners to find out anytime and anyplace. It allows the event of good learning content through the applying of sound educational style principles to dead analyze the essential necessities of learning also as learning objectives. Fundamentally, there are 2 classes of e-Learning:

Synchronous and Asynchronous. Synchronous e-Learning is once the learners and therefore the teacher act with one another in period of time, from completely different locations. Whereas Asynchronous eLearning is once learners complete self-paced on-line coaching. During this case, the learner and therefore the teacher do not seem to be on-line at constant time [27].

Synchronous e-Learning is time period learning. In synchronous learning, the learners and also the teacher square measure on-line and move at constant time from completely different locations. They deliver and receive the training resources via mobile, video conference, net, or chat. During this variety of learning the participants will share their ideas throughout the session and move with one another and that they get elaborated queries and solutions. Synchronous e-Learning is gaining quality due to improved technology and net information measure capabilities. Learning from the sources includes virtual classroom, option to chat and video conferencing, webinars and sharing Application and Messaging instantly, to leverage effective educational strategies, tips to drive motivation and learner engagement within the virtual room, and different tips check this e-Learning course on increasing impact within the virtual room [28].

Asynchronous e-Learning is pause-and-resume quite learning. During this sort of e-Learning the learner and therefore the teacher cannot be on-line at same time. Asynchronous e-Learning might use technologies like email, blogs, discussion forums, e-Book's CDs, DVDs, etc. Learners might learn at any time, transfer documents, and chat with academics \& additionally with co-learners. In fact, several learners like asynchronous rather than synchronous learning as a result of learners will take on-line courses to find out at their desirable time by not effecting their daily commitments. Learning from the sources includes Self-paced on-line courses, discussion forums and teams Message boards [29].

Although e-learning has unfolded its roots way and wide, only a few people are aware that there are a unit numerous forms of e-learning. Besides Asynchronous and Synchronous on-line Learning, there are other alternative forms of e-learning [30]:

Computer-Assisted Instruction (CAI):Computer-assisted coaching strategies use a mixture of transmission like text, graphics, sound, and video so as to boost learning. The first worth of CAI is interactivity - it permits students to become active learners rather than passive learners, by utilizing numerous strategies like quizzes and different computer-assisted teaching and testing mechanisms. Most schools today, each on-line and ancient, use completely different variations of computer-assisted learning to facilitate the event of skills and data in their students [31].

Computer Managed Learning (CML): Computer managed learning systems operate through info databases. These databases contain bits of data that the coed should learn, beside variety of ranking parameters that permits the system to be personalised in keeping with the preferences of every student. As a result of two-way communication between the coed and also the laptop, determinations are often created on whether or not the coed achieved their learning goals on a satisfactory level. If not, then the processes are often perennial till the coed has achieved their desired learning goals [32].

Adaptive E-learning: It could be a new and innovative sort of e-learning, that makes it doable to adapt and plan learning materials for every individual learner. Taking variety of parameters like student 
performance, goals, abilities, skills, and characteristics into thought, adaptive e-learning tools enable education to become a lot of individualised and student-centered than ever before [33].

Linear E-learning: When relating human-computer interaction, linear communication implies that data passes from sender to receiver, while not exception. Within the case of e-learning, this becomes a really limiting issue, because it does not permit two-way communication between academics and students. This kind of e-learning will have its place in education, though it is turning into less relevant with time. Causing coaching materials to students through TV and radio programs square measure classic samples of linear e-learning [34].

Fixed E-learning: This type of learning has been the quality in ancient lecture rooms for thousands of years, however it is not ideal in e-learning environments. That is as a result of fastened e-learning does not utilize the dear period of time information gained from student inputs. Analyzing every student on an individual basis through their information and creating changes to the materials consistent with this information results in higher learning outcomes for all students [35].

Collaborative online Learning: This may be a fashionable sort of learning technique, through that multiple students learn and accomplish their learning objectives along as a gaggle. Students have to be compelled to work along and observe cooperation so as to realize their common learning objectives. It expands on the thought that information is best developed within a gaggle of people wherever they will move and learn from one another [36].

Interactive online Learning: It permits senders to become receivers and contrariwise, effectively sanctioning a two-way communication between the parties concerned. From the messages sent and received, the academics and students will create changes to their teaching and learning strategies. For this reason, interactive e-learning is significantly a lot of common than linear, because it permits academics and students to speak a lot of freely with one another [37].

Individual online Learning: Individual learning during this context refers to the number of scholars collaborating in achieving the training goals, instead of the student-centeredness of the fabric. This sort of learning has been the norm in ancient school rooms for thousands of years. Once practising individual learning, the scholars study the training materials on their own (individually), and that they square measure expected to fulfill their learning goals on their own. This type of learning is not ideal for developing communicative skills and cooperation skills in students, because it mostly focuses on students learning severally, while not communication with different students. Therefore, a lot of fashionable approach is critical to supervene upon the communicative of skills and proficiencies [38].

\section{Learning Management Systems (LMS)}

A learning management system could be a software-based or SaaS platform that facilitates the management, administration, documentation, tracking, reporting, automation and delivery of educational courses, employment programs, or learning and development programs. In short, it helps to deliver coaching materials to numerous audiences - assume everything from on-line courses to time period instruction sessions. The most systems these days will even be accessed via smartphone [40]. The coaching management system thought emerged directly from e-Learning. Although the first LMS appeared among the pedagogy sector, the majority of the LMSs of late consider the corporate market. Learning Management Systems structure the largest section of the coaching system market. The first introduction of the LMS was among the late Nineties [41]. 
Learning management systems were designed to spot coaching and learning gaps, utilizing analytical knowledge and reportage. LMSs are centred on online learning delivery however support a spread of uses, acting as a platform for online content, together with courses, each asynchronous primarily basedand synchronous based. An LMS might provide room management for instructor-led coaching or a flipped room, utilized in educational activity, however not within the company area. Trendy LMSs embody intelligent algorithms to form machine-controlled recommendations for courses supported a user's ability profile still as extract meta-data from learning materials so as to form such recommendations even more appropriate. LMS platforms square measure used globally, across multiple completely different industries and for a spread of various enterprise learning use cases. LMS adoption has been on the increase for the past many years all round the world. In fact, the world LMS market is anticipated to grow at a CAGR of pure gold year on year, therefore if you are not friends along with your LMS resolution nonetheless, it is most likely time to induce familiar with. Here square measure 2 key varieties of LMS users [42]:

Administrators: Administrators have the access to manage the LMS, that involves a mix of multiple tasks: overseeing course management, content management (creating coaching courses and learning plans or contacting third party content providers), assignment specific learner teams to specific learning plans, and following their learning outcomes and progress.

Learners: Customers, partners, members, or employees stay on the receiving end of learning initiatives. Learners have the access to an LMS measurable to see their course catalog, complete allotted courses, and any evaluations, and live their own progress. The simplest LMS solutions make sure that this access encompasses an efficient journey and flow and is on-demand, to form it as simple as potential for learners to induce what they have. Learners will be allotted coaching on a private basis, or in keeping with their job perform, and/or role during a company's structure.

Learning management systems centralise, deploy, and live learning activities. A progressive learning management system supports a range of internal and external company use cases, including: Training and development of Customers, partners \& members, Employee onboarding, development and retention, compliance training and sales enablement. There are several advantages and benefits to each business and their learners once implementing an LMS. Reduces learning and development prices, curtail training/ on boarding time for workers, customers, and partners, Leverage AI to free-up time for L\&D directors, maintain compliance, track learner progress, and live however learning impacts structure performance. Some of the important highlights that an LMS mustcomprise: Artificial Intelligence (AI), Robotic admin responsibilities, Platform alliance, Customized learning directions, Perceptive user edge, Curriculum management, Endorsements and retraining, Content assimilation, interoperability and marketplace, Gamification, Integrations, and Mobile learning, Micro and social learning, Multi-domain, and reporting, and Globalisation [43].

\section{The Impact of E-Learning - The Conclusion}

E-Learning is not a brand-new thought, however not many of us acknowledge the impact it is creating on academic platforms. Since education is aimed toward life development, e-Learning may be a privilege which will boost improvement across fields of information and innovations. E-Learning includes online courses, tutorials, and everything that is obtainable within the on-line or offline digital formats. However, e-Learning remains in its growth part and holds tremendous potential for developing countries. However, it needs large amounts of monetary and human resources input. the expansion of e-learning 
is sort of completely dependent on the advancements in corresponding technologies. E-learning should not be merely a current incarnation of correspondence courses if its implementation is to totally utilise the affordances of technology. Models to gauge the effectiveness of e-learning square measure still to be developed and formed. Although there are several blessings related to e-learning, the disadvantages too have to be compelled to be eliminated before its full potential are often accomplished. We have seen that it is necessary to base the full price calculations on variable prices, fixed costs, and also the range of participants. Finally, there remains Cost-Benefit Analysis: during this approach, all outcomes are translated into financial values. The favored coaching ROI is truly one kind of price profit Analysis. Going by the trends witnessed in its growth, it is potential for e-learning to become a standard kind of education within the years to return. E-Learning clearly indicates a shift from pedagogue-controlled room learning and pedagogue management e-learning to a mixture of approaches that features pedagogue control once acceptable. It is vital to notice that this is often a remarkable, however maybe not shocking observation, that suggests that the generation of scholars in their study is also still traditional learners and have not however resorted to such learning.

\section{REFERENCES}

1. Finger, G. 2007. Active Reading! Active Learning! Reaffirming the Thirst for Knowledge in the 21st Century: The implications of connectivism in a digital age. Presentation at Somerset Celebration of Literature, Radisson Resort Gold Coast, Palm Meadows, 13 March 2007.

2. Gardner, H. 2000. Intelligence Reframed: Multiple Intelligence for the $21^{\text {st }}$ Century, New York.

3. Perraton, H., Creed, C. and Robinson, B. 2002. Teacher education guidelines: Using open and distance learning. UNESCO.

4. Alarifi, Y. 2003. E-learning Technology: Promising Method, E-learning International Conference, Saudi Arabia 23-25/3/2003, Riyadh: King Faisal School.

5. Alkalifah, H. 2008 From E-learning Management to Personal Learning Environments, E-learning Conference, Saudi Arabia 24-26/5/2008, Riyadh: King Saud University.

6. Almosa, A. and Almubarak, A. 2005. E-learning Foundations and Applications, Saudi Arabia: Riyadh.

7. Downes, T. and Fatouros, C. 1995. Learning in an Electronic World: Computers in the Classroom. Newtown: Primary English Teaching Association.

8. Wang et al. 2005. Measuring e-learning systems success in an organizational context: Scale development and validation: pp. 3-16. Available online athttps:/www.google.com/?gws_ $\mathrm{rd}=\mathrm{ssl} \# \mathrm{q}=$ the + study + by + Wang + et + al. $\% 2 \mathrm{C}+2007+$ on+ELearning + Systems + Success $+($ ELSS $)$. Accessed on $19 / 09 / 2016$.

9. Nichols, M. 2003. A Theory for E-Learning. Journal of Educational Technology and Society, 6: 1-10.

10. Department for Education and Skills (DfES). 2004. Five Year Strategy for Children and Learners, July 2004. Retrieved from the World Wide Web on 27 May 2007 at http://www.dfes.gov.uk/ publications5yearstrategy/docs/DfES5Yearstrategy1.rtf.

11. Watkins, C. 2003. Learning: a sense-maker's guide (London, Association of Teachers and Lecturers). 
12. Allan, K. 2008 A Primer on E-learning. Future lab innovation in education, [online] Available from: http://www.futurelab.org.uk/resources/publications-reportsarticles/

13. Khan, B.H. 2005. Managing E-learning: Design, Delivery, Implementation and Evaluation, Hershey, PA: Information Science Publishing.

14. Coffield, F., Moseley, D., Hall, E. and Ecclestone, K. 2004. Learning styles and pedagogy in post- 16 learning, A systematic and critical review. Learning and skills research center, 2004.

15. Weis, D. and Schank, M.J. 2000: An instrument to measure professional nursing values. Journal of Nursing Scholarship, 32(2): 201-204.

16. Almuheisin, A. 2002. E-learning ... Luxury or Necessity, Future's School Conference, Saudi Arabia 22-24/10/2001, Riyadh: King Saud University. [online] Available from: http://www.ituarabic.org/eeducation/doc3-idsc.doc[Accessed 22 /6/2008].

17. Aldrich, C. 2004 Simulations and the Future of Learning: An Innovative (and Perhaps Revolutionary) Approach to E-learning, San Francisco: Pfeiffer.

18. Cross, M. and Adam, F. 2007. ICT Policies and Strategies in Higher Education in South Africa: National and Institutional Pathways', Higher Education Policy, 20(1): 73-95.

19. Hilbert, M. 2012. Towards a conceptual framework for ICT for Development: lessons learned from the Latin American “Cube Framework". Info.Tech. \& Internat. Dev. ITID, 8, 4, pp 243-259; http:// itidjournal.org/itid/article/viewFile/967/408

20. Modal, A. and Mete, J. 2012. ICT in Higher Education: Opportunities and Challenges, Bhatter College Journal of Multidisciplinary Studies, 2.

21. Mason, R. and Rennie, F. 2006. Elearning: The Key concepts. Oxon, UK: Routledge.

22. Moore, M.G. and Kearsley, G. 1996. Distance education: A systems view. Belmont, CA: Wadsworth.

23. Porter, L.R. 1997. Creating virtual classroom: Distance learning with the Internet. New York: Wiley.

24. Leithwood, K. and Jantzi, D. 2000. The effects of transformational leadership on organizational conditions and student engagement with school, Journal of Educational Administration, 38(2): 112-129.

25. Caswell, B. and Bielaczyc, K. 2002. Knowledge Forum: altering the relationship between students and scientific knowledge, Education, Communication \& Information, 1(3): 281-305.

26. Crawford, B., Krajcik, J. and Marx, R. 1999. Elements of a community of learners in a middle school science classroom, Science Education, 83(6): 701-723.

27. CommLab India Bloggers. 2020. What are Synchronous and Asynchronous e-Learning? Available at: https://blog.commlabindia.com/elearning-design/types-of-elearning (Accessed: 5th January 2021).

28. G-Cube. 2021. Different Types of e-Learning and What Suits Me Best, Available at: https://www.gcsolutions.net/resources/articles/different-types-of-e-learning-and-what-suits-me-best (Accessed: 5 th January 2021 ).

29. Sander Tamm. 2019. Types of E-Learning -These are the 10 distinguishable types of e-learning, Available at: https://e-student.org/types-of-e-learning/(Accessed: 20 ${ }^{\text {th }}$ December 2020). 
30. Lewis Keegan. 2020. 10+ Different Types of e-Learning Revealed, Available at: https://skillscouter. com/types-of-e-learning/(Accessed: $10^{\text {th }}$ January 2021).

31. Anohina, A. 2005. Analysis of the terminology used in the field of virtual learning. Journal of Educational Technology \& Society, 8(3): 91-102.

32. Jacqueline, B., Julia, R. and Alison, W. 2009. 'The effect of computer-assisted learning versus conventional teaching methods on the acquisition and retention of hand-washing theory and skills in pre-qualification nursing students: a randomised controlled trial', International Journal of Nursing Studies, 47(3): 287-294.

33. Jose, O. 2016. What is adaptive e-Learning? Available at: https://www.iadlearning.com/adaptive learning/\#: :text=The\%20term\%20adaptive\%20e\%2DLearning,goal\%20of\%20maximizing\%20 their\%20performance. (Accessed: 7th January 2021).

34. Granger, Benjamin P. 2012. "Enhancing Training Outcomes in the Context of e-Learning: The Impact of Objective Learner Control, Training Content Complexity, Cognitive Load, Learning Goal Orientation, and Metacognitive Strategies". Graduate School Theses and Dissertations.

35. Imed, B. 2020. What Is e-Learning? Types, Advantages, and Drawbacks, Available at: https://www. guide2research.com/research/what-is-elearning\#: :text=In\%20fixed $\% 20$ elearning $\% 2 \mathrm{C} \% 20$ the $\% 20$ content, student's\%20learning\%20pace\%20or\%20preferences. (Accessed: $5^{\text {th }}$ January 2021).

36. Michael, H. 2018. Reasons Why Collaborative Online Learning Activities Are Effective, Available at: https://elearningindustry.com/collaborative-online-learning-activities-reasons-effective(Accessed: 5th December 2020).

37. Isha, S. 2019. 4 Examples of Interactive e-Learning Activities To Enhance Learner Engagement, Available at: https://elearningindustry.com/interactive-elearning-activities-enhance-learner-engagement4-examples (Accessed: $5^{\text {th }}$ January 2021).

38. Klaczynski, P., Gordon, D.H. and Fauth, J. 1997. Goal-oriented critical reasoning and individual differences in critical reasoning biases. Journal of Educational Psychology, 89(3): 470-485.

39. Ellis, Ryann K. 2009. Field Guide to Learning Management, ASTD Learning Circuits, archived from the original on 24 August 2014, retrieved 5 July 2012.

40. Davis, B., Carmean, C. and Wagner, E. 2009. "The Evolution of the LMS: From Management to Learning". The e-Learning Guild Research.

41. Lin, Sandi. 2015. "SaaS Learning Management System: Is your LMS Truly SaaS? - e-Learning Industry". e-Learning Industry. (Accessed: $4^{\text {th }}$ February 2017).

42. Reanna, M 2020. What is an LMS? Available at: https://www.docebo.com/blog/what-is-learningmanagement-system/ (Accessed: $11^{\text {th }}$ January 2021). 
